\title{
Population Fluctuation of Plant Parasitic Nematodes Associated With Grapevine under Hi-Tech and Low-Tech Polyhouse Conditions
}

\author{
T.H. Askary ${ }^{1 *}$, A. Khalii ${ }^{2}$, A.A. Khan ${ }^{1}$ and N. Nazir ${ }^{2}$ \\ ${ }^{1}$ Division of Entomology, ${ }^{2}$ Division of Fruit Sciences, Sher-e-Kashmir University of \\ Agricultural Sciences and Technology, Main Campus, Shalimar, \\ Srinagar-190025, Jammu and Kashmir, India \\ *Corresponding author
}

\begin{tabular}{|l|}
\hline Ke y w or d s \\
$\begin{array}{l}\text { Grapevine, Nematode, } \\
\text { Polyhouse, Hi-tech, Low- } \\
\text { tech, Rhizosphere }\end{array}$ \\
\hline Article Info \\
\hline $\begin{array}{l}\text { Accepted: } \\
16 \text { April } 2018 \\
\text { Available Online: } \\
10 \text { May } 2018\end{array}$ \\
\hline
\end{tabular}

\section{A B S T R A C T}

Soil samples were collected from the rhizosphere of two months old grapevine grown in hi-tech and low-tech polyhouse. Forty samples each from hi-tech and low-tech polyhouse were withdrawn at four intervals i.e. May, June, July and August for two consecutive years 2016 and 2017 and processed in the laboratory for the determination of nematodes. Among the five nematode genera identified, four were plant parasitic viz., lesion nematode, Pratylenchus spp., stunt nematode, Tylenchorhynchus spp, reniform nematode, Rotylenchulus spp. and Tylenchus spp. The free living nematode identified was Rhabditis spp. Nematode population was maximum in low-tech as compared to hi-tech polyhouse nursery. The population of all the nematodes increased gradually in the soil with the passage of time i.e. from May to August. Among the plant parasitic nematodes the population of Tylenchorhynchus spp. was maximum followed by Pratylenchus spp., Tylenchus spp. and Rotylenchulus spp. both in low-tech and hi-tech polyhouse. In hi-tech polyhouse the population of Tylenchorhynchus spp. was maximum i.e. 84 and 87 in August, 2016 and 2017, respectively whereas it was minimum for Rotylenchulus spp. i.e. 28 and 35 in August, 2016 and 2017, respectively. Similar was the case in low-tech polyhouse where also the population of Tylenchorhynchus spp. was maximum i.e. 148 and 144 and population of Rotylenchulus spp. was minimum i.e. 49 and 64 in August, 2016 and 2017, respectively. Because of the high population of some plant parasitic nematodes encountered around the rhizosphere of grapevines, it is assumed that the plant parasitic nematodes form an important component of soil ecosystem and may be a contributing factor in declining health of these plants.

\section{Introduction}

Grapes (Vitis spp.) are considered a major commercial venture throughout the temperate region because of higher remuneration per unit area and the realization that grape consumption is essential for human health and nutrition. It is native to Asia Minor and the Caucasus region, was distributed throughout Europe, and is now extensively grown in the Mediterranean Basin, the subtropical regions of Australia, Southern Africa, and North and 
South America (Brown et al., 1993). During the year 2005-06, the highest percentage of world grape production was shared by Italy (12.6\%), followed by USA (10.5\%), France (10.0\%) and China (9.7\%), however India ranked first in productivity (25.4 ton/ ha), followed by USA (18.7 ton/ ha) (Kumar, 2007).

Plant parasitic nematodes are reported to be one of the major biotic constraints to grape production. These nematodes are serious concern for viticulturists as they divert nutrients from normal vine growth to supply their own needs, which in turn results in lack of vine vigour and reduced crop yield. The annual losses in the yield of grapes due to plant parasitic nematodes have been estimated 12.5\% (Sasser and Freckman, 1987). Not much information is available on the distribution of plant parasitic nematodes around the rhizosphere of grape in Kashmir valley. Hence, in the present study an attempt has been made to determine the types and densities of nematodes associated with grape cultivation in SKUAST-Kashmir, Srinagar.

\section{Materials and Methods}

\section{Collection of soil samples}

Soil samples were collected from two months old grape (Vitis vinifera) plants grown in hitech and low-tech polyhouse at SKUASTKashmir, Shalimar campus, Srinagar. The two polyhouses were at a distance of $50 \mathrm{~cm}$ from each other. Soil samples were collected on monthly basis at four different intervals i.e. May-June-July-August for two consecutive years i.e. 2016 and 2017. There were 10 microplots in each polyhouse. The size of each plot was $4 \times 3 \mathrm{~m}$ and they were prepared with $0.5 \mathrm{~m}$ wide and $0.25 \mathrm{~m}$ high bund (margins). A total 80 soil samples were collected from the rhizosphere of grape plants, of which 40 from hi-tech polyhouse which was managed and necessary inputs such as fertilizers, organic manures, weeding, irrigation were given in time and another 40 from low-tech polyhouse which was unmanaged and no necessary inputs or care was taken in this polyhouse. The samples were collected at a depth of $15-20 \mathrm{~cm}$ from the above soil surface, randomly from three places in a microplot and a composite sample was prepared, kept in a poly bag, tagged and brought in the laboratory for isolation of nematodes.

\section{Isolation of nematodes}

Population of nematodes was determined by using Cobb's decanting and sieving method (modified) followed by Baermann funnel technique (Southey, 1986). $500 \mathrm{ml}$ soil of each sample was sifted through a coarse sieve and processed separately. The soil sample $(500 \mathrm{~g})$ was mixed in 5 litres of water in a plastic bucket.

The soil-water mixture was stirred and then allowed to stand for 1-2 minutes. The suspension was decanted over a combination of 3 sieves (60, 200 and 500 mesh), the catch from the finest sieve was carefully washed and transferred to a beaker.

A small coarse sieve with two layers of wet paper towels was kept in a Baermann funnel filled with water. The nematode suspension from the beaker was gently poured onto the sieve and allowed to stand overnight. The nematodes because of the random and continuous movement migrate through the paper pores into the water and gradually settle down in the bottom of rubber tubing of the funnel. The nematode suspension recovered from the Baermann funnel was taken into a beaker. The population of nematode was assessed for each month with the help of Syracuse counting dish. The counting of nematode was performed under stereoscopic microscope. 


\section{Identification of nematodes}

The nematodes thus collected were killed by hot water $\left(85{ }^{0} \mathrm{C}\right)$, then fixed in $\mathrm{TAF}$ (Triethelene Amine Formalin) (Courtney et al., 1955), water in specimens replaced by glycerin using the Seinhorst technique (Seinhorst, 1959), after which they were mounted in pure glycerin.

Permanent slides were prepared and nematodes were identified up to genera level. The study for identification of nematodes and photomicrographs were taken using Olympus CX 21 i microscope.

\section{Results and Discussion}

Among the five nematode genera identified, four were plant parasitic viz., lesion nematode, Pratylenchus spp. (Fig. 1), stunt nematode, Tylenchorhynchus spp. (Fig. 2), reniform nematode, Rotylenchulus spp. (Fig. 3) and Tylenchus spp. (Fig. 4 and 5). The free living nematode identified, belonged to the genera Rhabditis spp. (Fig. 6). Total nematode population including free living was maximum in low-tech as compared to hi-tech polyhouse nursery.

Among the plant parasitic nematodes the population of Tylenchorhynchus spp. was maximum followed by Pratylenchus spp., Tylenchus spp. and Rotylenchulus spp. both in low-tech and hi-tech polyhouse (Table 1). In hi-tech polyhouse the population of Tylenchorhynchus spp. was maximum i.e. 84 and 87 in August, 2016 and 2017, respectively whereas it was minimum for Rotylenchulus spp. i.e. 28 and 35 in August, 2016 and 2017, respectively. The population of Tylenchorhynchus spp. was also maximum in low-tech polyhouse where it was 148 and 144 in August, 2016 and 2017, respectively but the population of Rotylenchulus spp. was minimum i.e. 49 and 64 in August, 2016 and
2017, respectively. The population of all the nematodes increased gradually in the soil with the passage of time i.e. from May to August. In hi-tech polyhouse the total nematode population was 446 and 391 in May, 2016 and 2017, respectively whereas it was 814 and 832 in August, 2016 and 2017, respectively. Similar was in case of low-tech polyhouse where the total nematode population was 671 and 659 in May, 2016 and 2017, respectively whereas it was 1022 and 1078 in August, 2016 and 2017, respectively (Table 1).

The low population of nematodes in hi-tech polyhouse may be attributed to maintenance such as proper weeding and application of organic manures in soil whereas the high population of nematodes in low-tech was due to lack of maintenance which provided ample opportunity for nematodes to multiply and increase their population. The above mentioned and other parasitic nematodes have also been recorded as parasites of grapes both in nurseries as well as orchards by several workers (Quader et al., 2001; Téliz et al., 2007; Howland et al., 2014). Because of the high population of some plant parasitic nematodes encountered around the rhizosphere of grapevines, it is assumed that the plant parasitic nematodes may be a contributing factor in declining health of these plants.

Due to lack of information, diversity among the species of plant parasitic nematodes could not be compared, however it may be assumed that diversity varies considerably with habitat, area and the number of individuals (Askary et al., 2013, 2014). The present study on nematode community structure associated with grape cultivation indicates the plant parasitic nematodes form an important component of soil ecosystem. However, further investigation is needed for assessing the role of related ecological parameters in the management of plant parasitic nematodes. 
Table.1 Nematodes associated with the rhizosphere of grapevines at different intervals in Hi-tech and Low-tech polyhouses (Average population 500g soil)

\begin{tabular}{|c|c|c|c|c|c|c|c|c|c|c|c|c|}
\hline \multirow[t]{3}{*}{ Hi-Tech } & \multicolumn{12}{|c|}{ Population of plant parasitic and other nematodes } \\
\hline & \multicolumn{2}{|c|}{ Pratylenchus spp. } & \multicolumn{2}{|c|}{$\begin{array}{l}\text { Tylenchorhynchus } \\
\text { spp. }\end{array}$} & \multicolumn{2}{|c|}{$\begin{array}{l}\text { Rotylenchulus } \\
\text { spp. }\end{array}$} & \multicolumn{2}{|c|}{ Tylenchus spp. } & \multicolumn{2}{|c|}{$\begin{array}{l}\text { Saprozoic and } \\
\text { others }\end{array}$} & \multicolumn{2}{|l|}{ Total } \\
\hline & 2016 & 2017 & 2016 & 2017 & 2016 & 2017 & 2016 & 2017 & 2016 & 2017 & 2016 & 2017 \\
\hline May & 42 & 37 & 56 & 70 & 23 & 16 & 35 & 28 & 290 & 240 & 446 & 391 \\
\hline June & 60 & 66 & 73 & 79 & 25 & 19 & 40 & 41 & 430 & 418 & 628 & 623 \\
\hline July & 76 & 70 & 80 & 80 & 25 & 29 & 52 & 44 & 510 & 566 & 743 & 789 \\
\hline August & 76 & 70 & 84 & 87 & 28 & 35 & 56 & 50 & 570 & 590 & 814 & 832 \\
\hline \multicolumn{13}{|c|}{ Low-Tech } \\
\hline May & 70 & 80 & 74 & 82 & 36 & 31 & 51 & 58 & 440 & 408 & 671 & 659 \\
\hline June & 85 & 96 & 115 & 110 & 36 & 40 & 65 & 61 & 570 & 580 & 871 & 887 \\
\hline July & 94 & 100 & 120 & 144 & 41 & 50 & 70 & 69 & 685 & 706 & 1010 & 1069 \\
\hline August & 102 & 115 & 148 & 144 & 49 & 64 & 73 & 80 & 650 & 675 & 1022 & 1078 \\
\hline
\end{tabular}


Fig.1 Anterior part of Pratylenchus sp. showing cephalic region flattened anteriorly

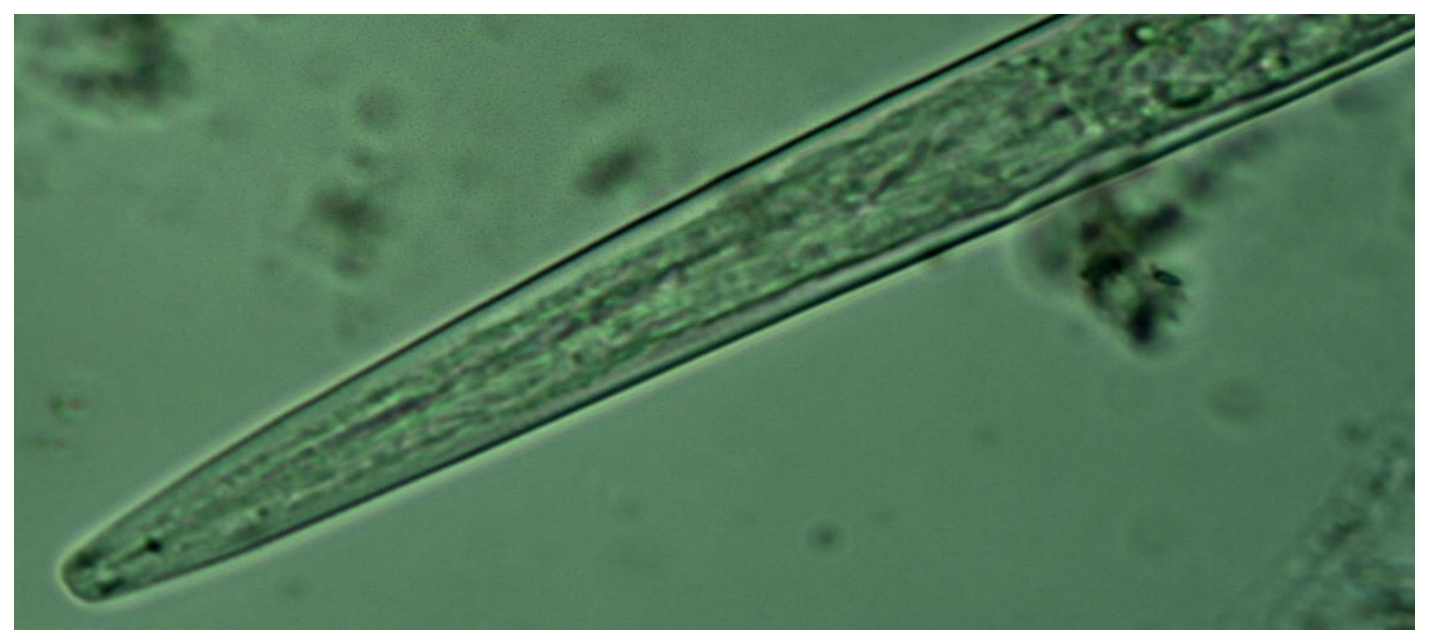

Fig.2 Tylenchorhynchus sp. - A full view of adult female

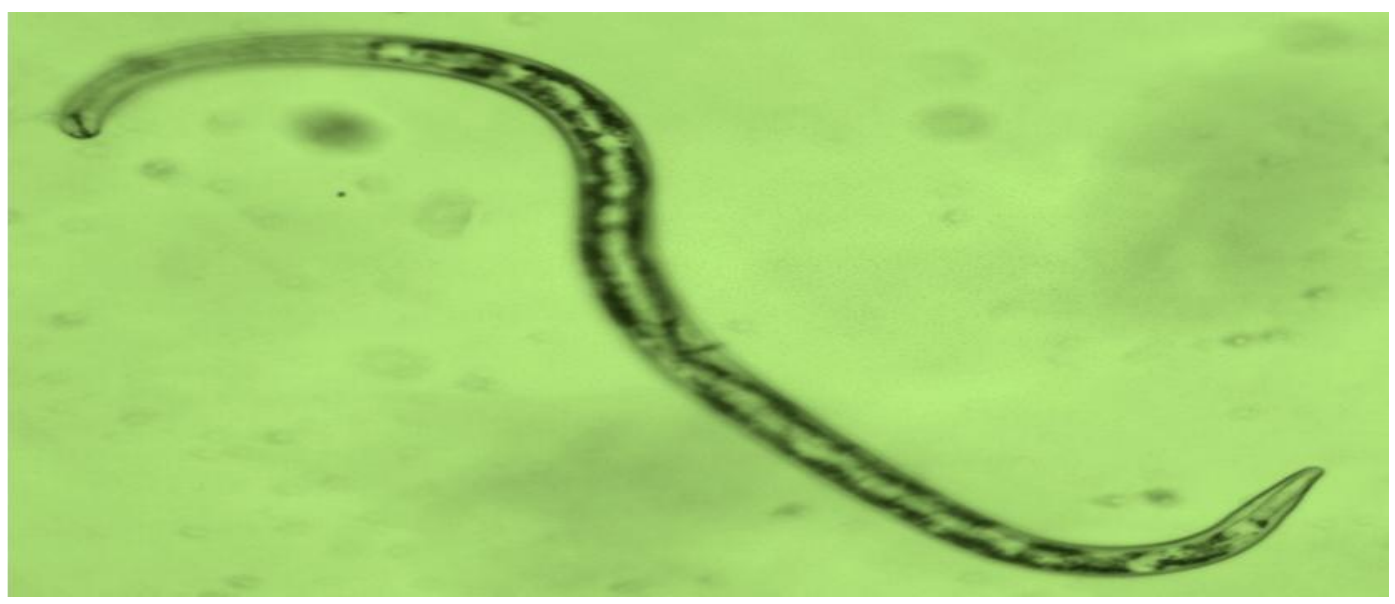

Fig.3 Rotylenchulus sp.-A full view of pre-adult female

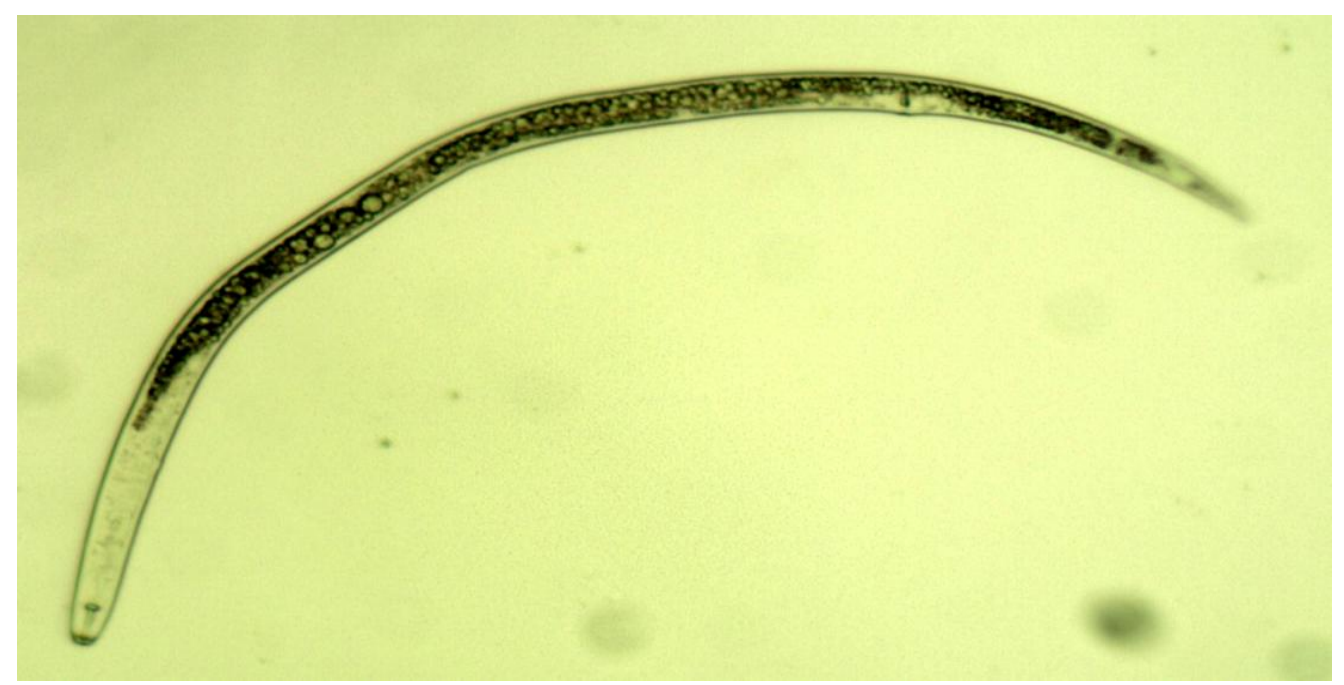


Fig.4 Tylenchus sp.-A full view of adult female with filiform tail

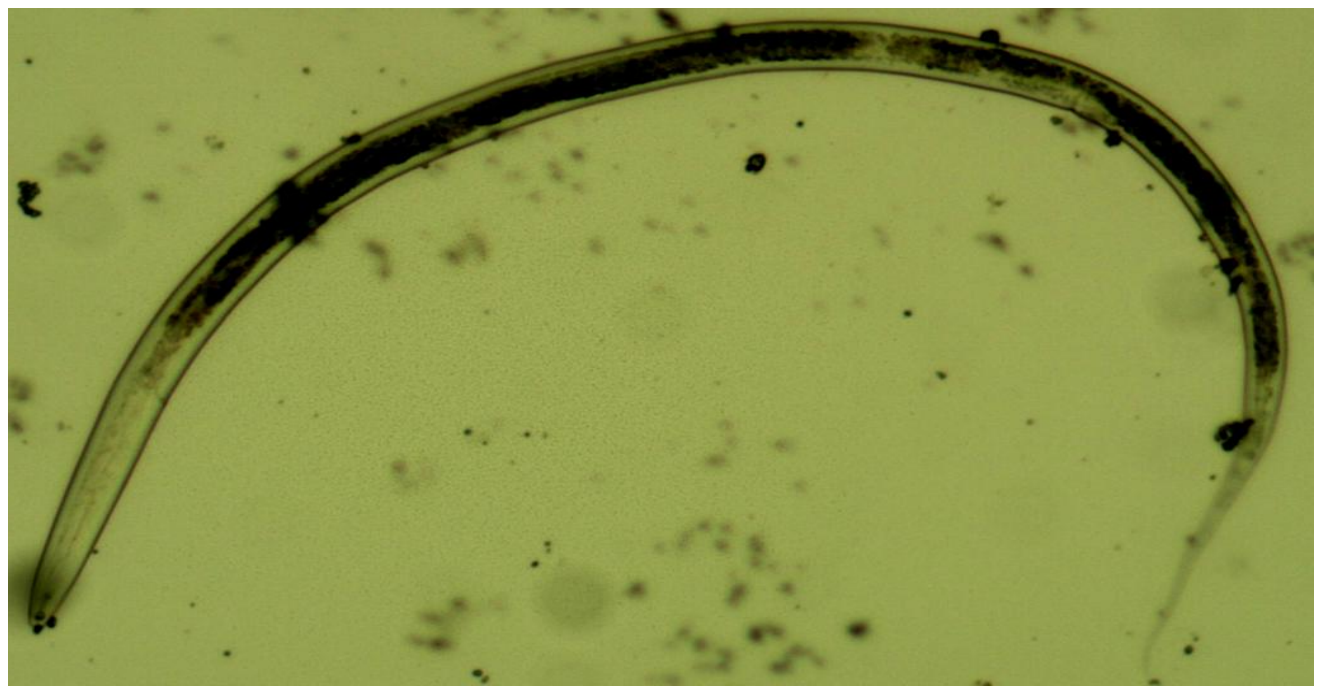

Fig.5 Posterior portion of adult male-gubernaculum and spicule present, bursa adanal (A), Variation in tail of Tylenchus sp. - ventrally arcuate (B), pointed (C)

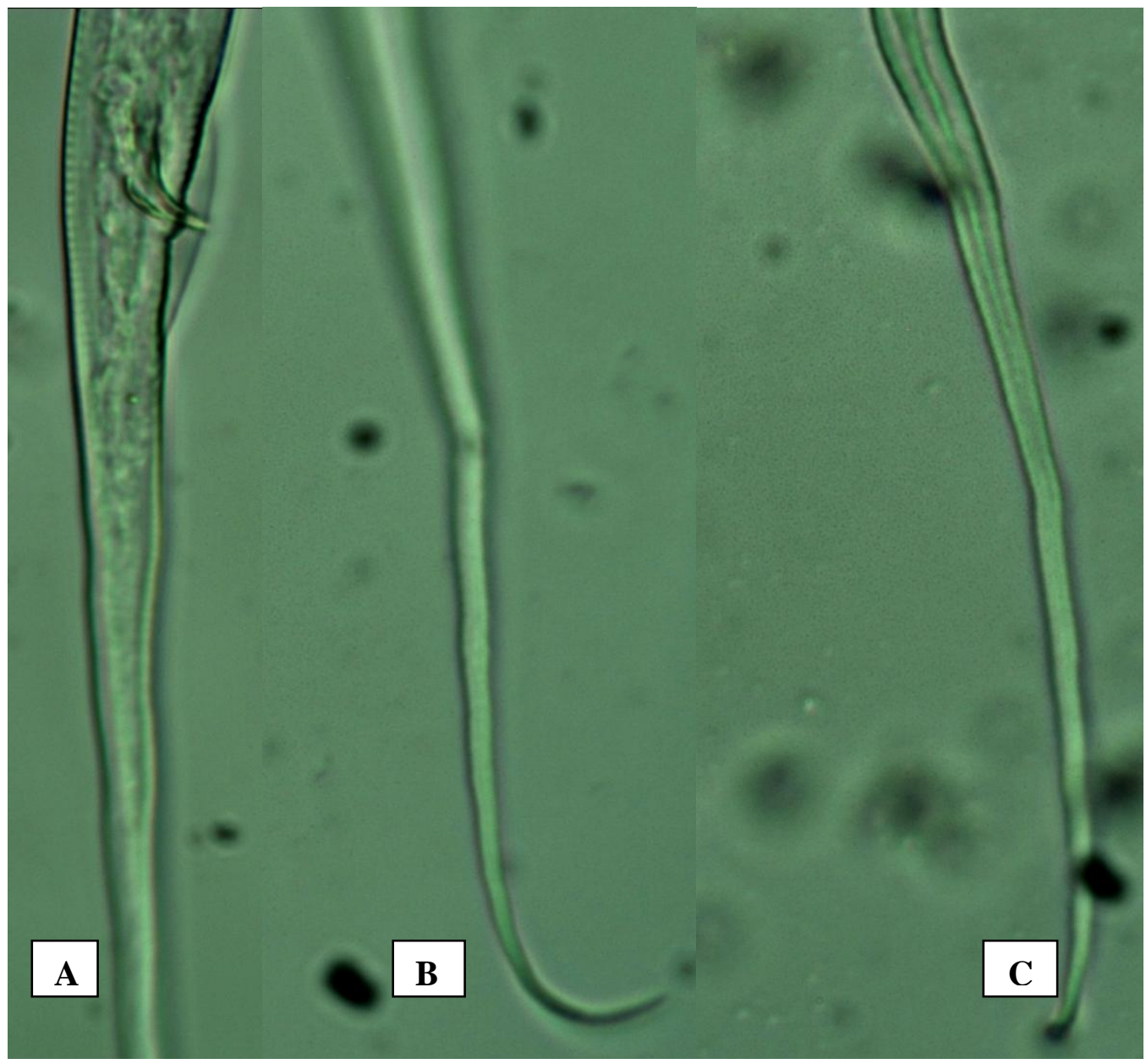


Fig.6 Anterior view of Rhabditis sp. with tubular stoma and bulbular oesophagous

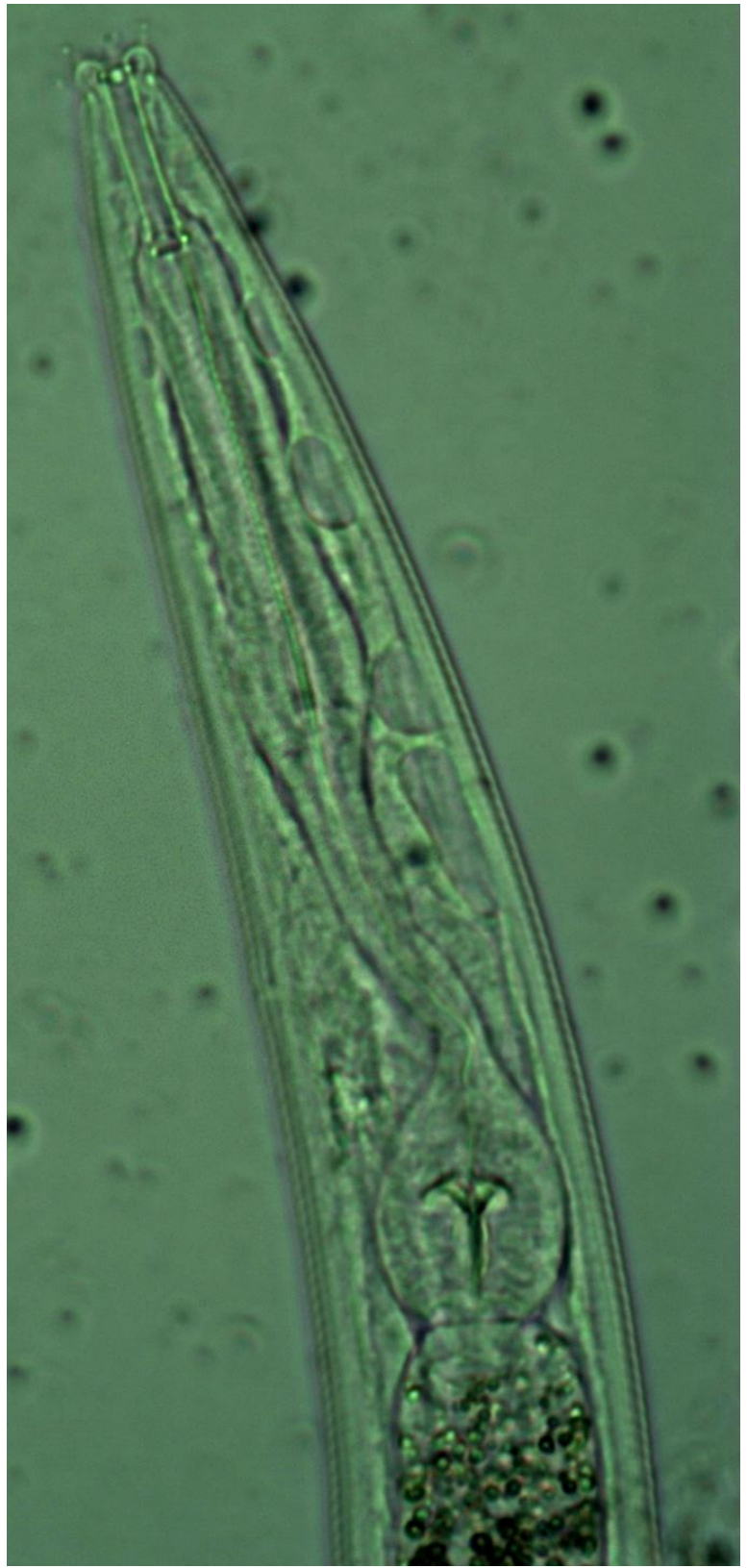

\section{Acknowledgements}

This research is supported in part by MIDH project running in the Division of Fruit Sciences, SKUAST-Kashmir, Srinagar, India. We are also thankful to Division of Entomology, SKUAST-K, Srinagar for providing laboratory facilities to conduct the research work and sophisticated microscope needed for study and photography of nematode specimens isolated during the course of investigation.

\section{References}

Askary, T.H., Waliullah, M.I.S., Mir, M.M. (2014) Distribution of phytonematodes associated with stone and nut fruits in Kashmir valley, India. Journal of Applied Horticulture 16, 136-140. 
Askary, T.H., Waliullah, M.I.S., Mir, M.M. and Banday, S.A. (2013). Population dynamics of plant parasitic nematodes associated with Pome fruits. Annals of Plant Protection Sciences 21, 157-159.

Brown, D.J.F., Dalmasso, A. and Trudgill, D.L. (1993) Nematode pests of soft fruits and vines. In: Evans, K., Trudgill, D.L. and Webster, J.M. (eds.) PlantParasitic Nematodes in Temperate Agriculture. CAB International, Wallingford, UK, pp. 427-462.

Courtney, W.D., Polley, D. and Miller, V.I. (1955). TAF an improved fixative in nematode technique. Plant Disease Reporter 39, 570-571.

Howland, A.D., Schreiner, R.P. and Zasada, I. (2014) Spatial distribution of plantparasitic nematodes in semi-arid Vitis vinifera vineyards in Washington. Journal of Nematology 46, 321-330.

Kumar, B. (2007) Indian Horticulture Database 2006. National Horticultural Board, Gurgaon, Haryana, India, pp. 324.

Quader, M., Riley, I.T., and Walker, G.E. (2001) Distribution pattern of root-knot nematodes (Meloidogyne spp.) in South Australian vineyards. Australasian Plant Pathology 30, 357-360.

Sasser, J.N. and Freckman, D.W. (1987). A world perspective on nematology: The role of the society. In: Veech, J.A. and Dickson, D.W. (eds.) Vistas on Nematology. Society of Nematologists, Hyattsville, Maryland, USA, pp. 7-14.

Seinhorst, J.W. (1959). A rapid method for the transfer of nematodes from fixative to anhydrous glycerin. Nematologica 4 , 67-69.

Southey, J.F. (1986). Laboratory Methods for Work with Plant and Soil Nematodes. Her Majesty's Stationary Office, London (GB).

Téliz, D., Landa, B.B., Rapoport, H.F., Pérez Camacho, F., Jiménez-Díaz, R.M. and Castillo, P. (2007) Plant parasitic nematodes infecting grapevine in southern Spain and susceptible reaction to root-knot nematodes of rootstocks reported as moderately resistant. Plant Disease 91, 1147-1154.

\section{How to cite this article:}

Askary, T.H., A. Khalil, A.A. Khan and Nazir, N. 2018. Population Fluctuation of Plant Parasitic Nematodes Associated with Grapevine under Hi-Tech and Low-Tech Polyhouse Conditions. Int.J.Curr.Microbiol.App.Sci. 7(05): 2133-2140. doi: https://doi.org/10.20546/ijcmas.2018.705.248 